See discussions, stats, and author profiles for this publication at: https://www.researchgate.net/publication/304216066

\title{
Intraguild Competition of Three Noctuid Maize Pests
}

Article in Environmental Entomology · June 2016

DOI: 10.1093/ee/nvw068

CITATIONS

3

5 authors, including:

José Paulo Franco Bentivenha

Ihara

25 PUBLICATIONS 112 CITATIONS

SEE PROFILE

35

Silvana Paula-Moraes

University of Florida -UF

67 PUBLICATIONS 483 CITATIONS

SEE PROFILE
READS

124

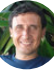

Edson L. L. Baldin

São Paulo State University

116 PUBLICATIONS 730 CITATIONS

SEE PROFILE

Some of the authors of this publication are also working on these related projects:

Evaluation of the anti-parasitary and insecticidal activities of benzofuran derivatives, and study of their gas-phase fragmentation reactions using tandem mass spectrometry View project

Spodoptera species of Brazil: biology, ecology, morphology and taxonomy View project 


\title{
Intraguild Competition of Three Noctuid Maize Pests
}

\author{
J. P. F. Bentivenha, ${ }^{1,2}$ E. L. L. Baldin, ${ }^{1}$ T. E. Hunt, ${ }^{3}$ S. V. Paula-Moraes, ${ }^{4}$ and \\ E. E. Blankenship 5 \\ 'Universidade Estadual Paulista, Faculdade de Ciências Agronômicas, Departamento de Proteção Vegetal, Botucatu, São Paulo, \\ Brazil 18610-307 (jpgfdsilva@gmail.com; elbaldin@fca.unesp.br), ${ }^{2}$ Corresponding author, e-mail: jpgfdsilva@gmail.com, \\ ${ }^{3}$ Department of Entomology, University of Nebraska-Lincoln, Haskell Agricultural Laboratory, Concord, NE 68728 (thunt2@ \\ unl.edu), ${ }^{4}$ Embrapa Cerrados, BR 020 Km 18, Planaltina, Distrito Federal, Brazil 73310-970 (silpaulamoraes@gmail.com), and \\ ${ }^{5}$ Statistics Department, University of Nebraska-Lincoln, Lincoln, NE 68583 (erin.blankenship@unl.edu)
}

Received 25 February 2016; Accepted 10 May 2016

\begin{abstract}
The western bean cutworm Striacosta albicosta (Smith), the fall armyworm Spodoptera frugiperda (J. E. Smith), and the corn earworm Helicoverpa zea (Boddie) (Lepidoptera: Noctuidae) are among the major lepidopteran pests of maize in the United States, belonging to the same guild and injuring the reproductive tissues of this crop. Here, intraguild competition of these lepidopterans on non-Bt maize was evaluated through survival analysis of each species under laboratory and field conditions. Competition scenarios were carried out in arenas containing maize silk or ear tissue, using larvae on different stadium of development. Fitness cost competition studies were conducted to examine the influence of intraguild competition and cannibalism and predation rates on larval development. The survival of $S$. albicosta competing with the other species was significantly lower than in intraspecific competition, even when the larvae were more developed than the competitor. For $S$. frugiperda, survival remained high in the different competition scenarios, except when competing in a smaller stadium with $H$. zea. Larvae of $H$. zea had a high rate of cannibalism, higher survival when competing against $S$. albicosta than $S$. frugiperda, and reduced survival when the $H$. zea larvae were at the same development stadium or smaller than the competitors. Based on fitness cost results, the absence of a competitor for the feeding source may confer an advantage to the larval development of $S$. frugiperda and $H$. zea. Our data suggest that S. frugiperda has a competitive advantage against the other species, while S. albicosta has the disadvantage in the intraguild competition on non-Bt maize.
\end{abstract}

Key words: cannibalism, intraguild predation, western bean cutworm, fall armyworm, corn earworm

Maize (Zea mays L.) is one of the main agricultural crops worldwide and serves as a food resource for humans and livestock. The United States is the largest producer, responsible for almost $40 \%$ of global production (United States Department of Agriculture Foreign Agricultural Service [USDA FAZ] 2014). The noctuids Helicoverpa zea (Boddie, 1850), Spodoptera frugiperda (J. E. Smith, 1797), and Striacosta albicosta (Smith, 1888) are among the major lepidopteran pests of maize, causing significant losses in yield (Rule et al. 2014). These three species belong to the same maize ear-feeding guild (Root 1967). Larvae of $S$. frugiperda can cause injury during the whorl stage, but also infest ears and feed directly on the developing kernels (Siebert et al. 2012). Moths of H. zea oviposit on silks, and as soon as the larvae hatch they move to and feed on kernels (Burkness et al. 2010). Females of S. albicosta usually oviposit on pre-tassel maize (Seymour et al. 2004, Michel et al. 2010), while larvae subsequently feed on leaf and husk tissue, with kernels being the final feeding site (Paula-Moraes et al. 2012).
Previous studies have reported intraguild competition among maize pests (Seymour et al. 2004, Dorhout and Rice 2010). In addition, the occurrence of cannibalistic behavior during the immature stages of S. frugiperda and H. zea (Pierce 1995, Chapman et al. 2000) may intensify intraguild competition.

Cannibalism is a widespread behavior in nature, often favored under high population densities and when food is at low levels (Elgar and Crespi 1992), although it can occur even when food is not limiting (Polis 1981). This behavior can have significant benefits in nutritional and energetic terms (Alabi et al. 2009). It also may be advantageous for increasing the size, growth, and development of individuals (Polis 1981, Edgar and Crespi 1992), directly or indirectly through the removal of a competitor (Fox 1975, Polis 1981) or reducing the risk of predation (Chapman et al. 1999a, 2000). Cannibalism can have risks of injury or death by defense responses from conspecifics (i.e., individuals of the same species), and pathogens or parasites can be acquired through the consumption of 
infected conspecifics (Polis 1981). Specific instar predation can cause a reduction in inclusive fitness (Pfennig et al. 1993, Polis 1981), which can be beneficial by increasing the rate of development (Eickwort 1973). In addition, cannibalism is considered an important factor of the population dynamics in several species (Alabi et al. 2009). When the predation occurs between different species, it is intraguild predation, which is preying or feeding on an individual of another species sharing the same food source, and therefore is considered exploitative (Polis 1981, Wise et al. 2006).

Researches have sought to understand the intraguild competition and cannibalism characteristics in Noctuidae and their relationship to entomopathogenic virus and plants expressing Bt proteins (Horner et al. 2003, Chilcutt 2006, Dorhout and Rice 2010). However, studies are still scarce about the larval behavior of noctuid maize pests and their cannibalistic characteristics (Burkness et al. 2011). In addition, little is known about the intraguild competition and predation, particularly under field conditions (Dorhout and Rice 2010) where it is possible to investigate the interaction between insect ecology and environment (Chilcut 2006, Chilcutt et al. 2007). Studies involving intraguild competition under natural conditions on non-Bt maize, including involving $S$. frugiperda, which is known to often infest maize and have cannibalistic behavior, are also scarce. Therefore, more research is needed.

Larval competition and intraguild predation may be related to the recent expansion and population dynamics of S. albicosta in the United States. Until 2000, its incidence in maize was considered limited to regions of Colorado, Idaho, Kansas, Nebraska, Iowa, Utah, Arizona, New Mexico, Texas, Alberta, and Mexico (Douglass et al. 1957, Hagen 1962). Since 2000, the S. albicosta range expanded east into Iowa, Illinois, Minnesota, Missouri, Indiana, Michigan, and Ohio (Rice 2000, Dorhout and Rice 2004, Rice and Dorhout 2006, Michel et al. 2010), and ultimately into regions of New York and Quebec, Canada (DiFonzo and Hammond 2008, Michel et al. 2010, Hutchison et al. 2011). There are several factors that may be responsible for expansion of the pest's range, but the fact that European corn borer Ostrinia nubilalis (Hubner, 1796) has been effectually suppressed by Bt maize throughout the Midwest "Corn Belt" (Hutchison et al. 2010), and S. albicosta is not affected by several $\mathrm{Bt}$ proteins raises the hypothesis of pest replacement within $\mathrm{Bt}$ maize ears (Catangui and Berg 2006, Rice and Dorhout 2006, Hutchison et al. 2011). In the face of this, studies are needed to understand how intraguild competition among this species and the other maize lepidopterans can affect the prevalence of these species in crops (Binning et al. 2014).

The objective of this study was to evaluate larval interspecific and intraspecific competition among S. albicosta, S. frugiperda, and $H$. zea on maize under laboratory and field conditions using different scenarios of competition. We also evaluated the effects of intraguild competition on larval development and fitness costs.

\section{Materials and Methods}

\section{Lepidoptera Stock Colony}

During the months of June and August of 2014, a temporary colony S. albicosta was established at the University of Nebraska-Lincoln Haskell Agricultural Laboratory, Concord, NE, based on rearing methodology described by Paula-Moraes et al. (2013).

Larvae of $S$. frugiperda and H. zea were commercially acquired (Benzon Research Inc., Carlisle, PA) and held on corresponding artificial diets developed by USDA, Stoneville, MS. The temporary colonies of each species were maintained in the laboratory $\left(27^{\circ} \mathrm{C}\right.$ and a
Controls

photoperiod of16:8 [L:D] h; Horner et al. 2003, Malo et al. 2013), enabling a supply of larvae for the laboratory and field experiments.

\section{Intraguild Competition}

The intraguild competition study was performed in competition scenarios involving the three noctuid species (two in each combination). Assays were performed in the field and laboratory at the University of Nebraska-Lincoln Haskell Agricultural Laboratory, Concord, NE, during the crop season of 2014. Competition studies were conducted in different sites (plastic cup in laboratory, plastic containers in laboratory, and maize ears in field), diet (non-Bt maize silk and maize ear), and in 21 competition scenarios as described in Table 1 . The effects of intraguild competition and cannibalism and predation on development of larvae were evaluated by fitness cost study. The effect of Bt proteins in the survival and cannibalism behavior were eliminated using only non-Bt hybrids.

\section{Laboratory Intraguild Competition}

Two competition studies were performed under laboratory conditions $\left(27^{\circ} \mathrm{C}\right.$ and a photoperiod of 16:8 [L:D] h). For the first, two larvae (based on scenarios of Table 1) were placed into transparent plastic cups (90 ml) containing only maize silk, and for the second competition study, larvae were placed in transparent plastic containers $(8 \mathrm{~cm}$ height by $30 \mathrm{~cm}$ diameter), containing a maize ear. Plastic cups were closed with a plastic lid containing small holes, while the plastic containers were sealed with plastic lid containing a central hole, coated with organdy fabric attached with hot glue.

Portions of maize silk ( $100 \mathrm{~g})$ and maize ears were collected from non-Bt field maize. Field areas were not surrounded by Bt maize, thus avoiding cross-pollination of non-Bt hybrid with Bt maize (Chilcutt and Tabashnik 2004, Burkness and Hutchison 2012). Maize silks were removed from the ears, sprayed with alcohol, with water, and then dried before being offered to larvae. Silks were changed daily to maintain quantity and quality tissue. The maize

Table 1. Scenarios of intraguild competition of noctuids in maize involving larvae of different sizes

Intraguild competition (21)

Treatments

S. albicosta (small) vs. H. zea (small)

S. albicosta (small) vs. H. zea (large)

S. albicosta (small) vs. S. frugiperda (small)

S. albicosta (small) vs. S. frugiperda (large)

S. albicosta (large) vs. H. zea (small)

S. albicosta (large) vs. H. zea (large)

S. albicosta (large) vs. S. frugiperda (small)

S. albicosta (large) vs. S. frugiperda (large)

H. zea (small) vs. S. frugiperda (small)

H. zea (small) vs. S. frugiperda (large)

H. zea (large) vs. S. frugiperda (small)

H. zea (large) vs. S. frugiperda (large)

S. albicosta (small) vs. S. albicosta (small) ${ }^{a}$

S. albicosta (small) vs. S. albicosta (large)

S. albicosta (large) vs. S. albicosta (large)

S. frugiperda (small) vs. S. frugiperda (small)

S. frugiperda (small) vs. S. frugiperda (large)

S. frugiperda (large) vs. S. frugiperda (large)

H. zea (small) vs. H. zea (small)

H. zea (small) vs. H. zea (large)

H. zea (large) vs. H. zea (large)

Small larva (second instar); large larva (fourth instar).

${ }^{a}$ Control treatments (Adapted from Dorhout and Rice 2010). 
ears were cleaned with alcohol, a portion of paper towel was fixed at the base of the ear using a rubber band, and the paper towel was moistened every two days to maintain ear turgidity. Ears in phenological stage R1 were used to obtain silks, and ears between stages R2 (blister stage) and R3 (milk stage) were used for the on-ear scenarios (Ritchie et al. 1993).

The larvae used in this study were removed from the diet one hour before the infestation. Each plastic cup or container was considered one replicate, with 20 replicates per scenario for both arenas in a completely randomized design. For the competition study with maize silk, evaluations of larval survival were performed daily during a period of $10 \mathrm{~d}$. For the competition study using maize ears, the evaluations of larval survival were performed $10 \mathrm{~d}$ after infestation due to the difficulty in accessing the larvae in the ear every day.

\section{Fitness Cost Evaluation}

Surviving larvae from the different competition scenarios in laboratory assays (maize silk, and plastic containers) were kept isolated in the same plastic containers and with the same food source until pupation. When the pupae were $2-3 \mathrm{~d}$ old, individuals were sexed and weighed on an analytical scale (model AY 220 0.0001G, Shimadzu Corporation, Kyoto, Japan), and maintained until adult emergence to verify pupal viability.

Larvae not submitted to competition and with the same age of those used in the competition scenarios were held singly in the same plastic containers and fed with the same food source. These larvae were used as a control in the statistical analysis for fitness cost.

\section{Field Intraguild Competition}

Field competition studies were carried out on two different maize planting dates, 21 May and 4 June of 2014. Both competition studies were conducted in non-Bt field maize (hybrid Channel 208-71R) grown using standard agronomic practices recommended for the region ( $22^{\circ} 82^{\prime} 48^{\prime \prime} \mathrm{S}, 48^{\circ} 42^{\prime} 80^{\prime \prime} \mathrm{W}, 720 \mathrm{~m}$ altitude). During the competition study were maintained the fertilizing and irrigation management practices to ensure optimum growth until the reproductive maize stages (Ritchie et al. 1993). Natural infestation of $S$. frugiperda, H. zea, and S. albicosta were monitored, and although very infrequent, when eggs or larvae were detected they were eliminated.

For each planting date, an area of $\sim 5,000 \mathrm{~m}^{2}$ was divided into five blocks, evenly spaced, with 21 plots each (corresponding to competition scenarios), totaling 105 plots. Five replicates were established in each plot in a randomized complete block design, totaling 525 scenarios. Each plot was $12 \mathrm{~m}$ long with five rows, spaced $0.70 \mathrm{~m}$ apart, corresponding to $\sim 45 \mathrm{~m}^{2}$. In each plot, only the central rows were used for the competition scenario evaluations.

When the plants reached the physiological stage R2-R3, larval tweezers were used to infest the maize ears with larvae (Table 1). After the infestation, each ear was carefully covered with a porous cloth pollination bag ( 25 by $30 \mathrm{~cm}$; Paula-Moraes et al. 2013). The upper part of the bag was held to the stem of the maize plant with clips, leaving an internal space $(\approx 10 \mathrm{~cm})$ between the end of the ear and the end of the bag. The base of the pollination bag was also fixed to the stalk and firmly fixed at the node with clips to prevent larval escape. The survival of larvae was assessed $10 \mathrm{~d}$ after infestation.

\section{Statistical Analyses}

Data of larva survival in the scenarios were assessed for normality with Shapiro-Wilks tests. Data were tested using chi-square test $\left(\chi^{2}\right.$;
$P \leq 0.01$; CHISQoption, PROC FREQ, SAS Institute 2001) between the survival of scenario and its corresponding control. The control treatment for each competition scenario consisted of scenarios with individuals of the same species, in the same instars as larvae for the other treatments (Table 1).

Fitness cost data (weight and survival) were submitted to analysis of variance, with normality assessed using the Shapiro-Wilk test and homoscedasticity evaluated using Levene's test (Winer et al. 1991). When significant differences in the effects of the treatments were found, Fisher's LSD test $(P \leq 0.05)$ was used for mean comparison, using the statistical program PROC MIXED-SAS 9.2 (SAS Institute 2001).

\section{Results}

\section{Intraguild Competition}

Survival of S. albicosta in competition with S. frugiperda and H. zea in laboratory trials with maize silk was significantly lower than the control for all scenarios $(P<0.001)$ except for the scenario involving large $S$. albicosta and small $S$. frugiperda larvae, where the survival ranged between $70-100 \%$ (Table 2). When competing with $H$. $z e a, S$. albicosta had $0 \%$ survival in scenarios with small S. albicosta versus large $H$. zea and large versus large $H$. zea. In competition of small versus small $H$. zea, the survival was $20 \%$, while in large versus small $H$. zea survival was $70 \%$. Survival of S. albicosta against S. frugiperda was $0 \%$ in competition of large versus large, but was 35 and $10 \%$ for small versus small, and small versus large, respectively. In large S. albicosta versus small, survival reached $75 \%$. For the intraguild competition controls, S. albicosta reached $100 \%$ survival in almost in all scenarios, except for small versus large, with $80 \%$ survival of small larvae (Table 2 ).

Laboratory competition studies conducted on maize ears resulted in significantly lower survival of $S$. albicosta against $H$. zea and S. frugiperda in all scenarios of intraguild competition $(P<0.05$; Table 2). Survival in the conspecific competitions remained close to $100 \%$ across scenarios. In the first field competition study (Table 2), $S$. albicosta also had significantly lower survival when competing with $H$. zea and $S$. frugiperda in all scenarios $(P<0.05)$, with lowest survival when the $S$. albicosta larvae were small and its competitor large. In the controls, the survival of $S$. albicosta was $\geq 80 \%$. For the second field study, results were similar and S. albicosta continued to have significantly lower survival when competing with the other species $(P<0.05)$. Even when $S$. albicosta was larger than the competitor, $S$. albicosta survival rates were lower $(55.6 \%$ competing against S. frugiperda and $77.8 \%$ against $H$. zea). Survival of S. albicosta was $100 \%$ in all scenarios of competition with conspecifics.

Survival of $S$. frugiperda in competition with the other species on maize silk in scenarios of small versus small and large versus small did not differ from the intraspecific competition (Table 3). Survival of $S$. frugiperda for the competition between small versus large was significantly higher $(80 \%)$ when competing with S. albicosta $\left(\chi^{2}=20.71 ; \mathrm{df}=2 ; P<0.0001\right)$. Similarly, the survival of $S$. frugiperda when large versus large was significantly higher in competition with $S$. albicosta $\left(\chi^{2}=8.44 ; \mathrm{df}=2 ; P=0.0147\right)$, with $100 \%$ survival.

When confined to maize ears in the laboratory, significant differences in survival of $S$. frugiperda were observed only in the scenario of small versus small $\left(\chi^{2}=10.03 ; \mathrm{df}=2 ; P=0.0066\right)$, with significantly lower survival in intraspecific competition (Table 3). In other scenarios, the survival of $S$. frugiperda did not differ significantly among the different intraguild competitions. When larvae were 
Table 2. Intraguild competition scenarios between Striacosta albicosta against Spodoptera frugiperda, Helicoverpa zea, and in intraspecific competition, in maize silk and maize ear in laboratory, and in field

\begin{tabular}{|c|c|c|c|c|c|c|c|c|c|c|}
\hline \multirow[t]{3}{*}{ Site } & \multirow{2}{*}{\multicolumn{2}{|c|}{ Competition }} & \multirow{2}{*}{\multicolumn{2}{|c|}{$\begin{array}{c}\text { Survival of S. albicosta (control) } \\
\text { vs. S. albicosta }\end{array}$}} & \multicolumn{4}{|c|}{ Survival of $S$. albicosta } & \multirow[t]{3}{*}{$\chi^{2}$} & \multirow[t]{3}{*}{$P$} \\
\hline & & & & & \multicolumn{2}{|c|}{ vs. S. frugiperda } & \multicolumn{2}{|c|}{ vs. H. zea } & & \\
\hline & S. albicosta & Competitor & Live $(n)$ & $\%$ & Live $(n)$ & $\%$ & Live $(n)$ & $\%$ & & \\
\hline Silk & Small $^{a}$ & Small & $20(20)$ & 100.0 & $7(20)$ & 35.0 & $4(20)$ & 20.0 & 28.96 & $<0.0001$ \\
\hline Silk & Small & Large & $16(20)$ & 80.0 & $2(20)$ & 10.0 & $0(20)$ & 0.0 & 36.19 & $<0.0001$ \\
\hline Silk & Large & Small & $20(20)$ & 100.0 & $15(20)$ & 75.0 & $14(20)$ & 70.0 & 5.66 & 0.0589 \\
\hline Silk & Large & Large & $20(20)$ & 100.0 & $0(20)$ & 0.0 & $0(20)$ & 0.0 & 60.00 & $<0.0001$ \\
\hline Maize ear & Small & Small & $20(20)$ & 100.0 & $7(20)$ & 35.0 & $2(20)$ & 10.0 & 34.57 & $<0.0001$ \\
\hline Maize ear & Small & Large & $18(20)$ & 90.0 & $4(20)$ & 20.0 & $4(20)$ & 20.0 & 26.61 & $<0.0001$ \\
\hline Maize ear & Large & Small & $20(20)$ & 100.0 & $16(20)$ & 80.0 & $13(20)$ & 65.0 & 8.24 & 0.0163 \\
\hline Maize ear & Large & Large & $20(20)$ & 100.0 & $6(20)$ & 30.0 & $2(20)$ & 10.0 & 35.89 & $<0.0001$ \\
\hline 1st Field & Small & Small & $25(25)$ & 100.0 & $10(25)$ & 40.0 & $16(25)$ & 64.0 & 20.95 & $<0.0001$ \\
\hline 1st Field & Small & Large & $23(25)$ & 92.0 & $4(25)$ & 16.0 & $8(25)$ & 32.0 & 32.25 & $<0.0001$ \\
\hline 1st Field & Large & Small & $20(25)$ & 80.0 & $14(25)$ & 56.0 & $20(25)$ & 80.0 & 13.33 & 0.0013 \\
\hline 1st Field & Large & Large & $20(25)$ & 80.0 & $10(25)$ & 40.0 & $13(25)$ & 52.0 & 12.97 & 0.0015 \\
\hline 2nd Field & Small & Small & $18(18)$ & 100.0 & $9(18)$ & 50.0 & $10(18)$ & 55.5 & 12.53 & 0.0019 \\
\hline 2nd Field & Small & Large & $18(18)$ & 100.0 & $4(18)$ & 22.2 & $5(18)$ & 27.8 & 27.11 & $<0.0001$ \\
\hline 2nd Field & Large & Small & $18(18)$ & 100.0 & $10(18)$ & 55.5 & $14(18)$ & 77.8 & 10.28 & 0.0058 \\
\hline 2nd Field & Large & Large & $18(18)$ & 100.0 & $8(18)$ & 44.4 & $5(18)$ & 27.8 & 21.05 & $<0.0001$ \\
\hline
\end{tabular}

${ }^{a}$ Small (second instar); Large (fourth instar); first size, S. albicosta; second size, competitor.

Table 3. Intraguild competition scenarios between Spodoptera frugiperda against Striacosta albicosta, Helicoverpa zea, and in intraspecific competition, in maize silk and maize ear in laboratory, and in field

\begin{tabular}{|c|c|c|c|c|c|c|c|c|c|c|}
\hline \multirow[t]{3}{*}{ Site } & \multirow{2}{*}{\multicolumn{2}{|c|}{ Competition }} & \multirow{2}{*}{\multicolumn{2}{|c|}{$\begin{array}{c}\text { Survival of S. frugiperda (control) } \\
\text { vs. S. frugiperda }\end{array}$}} & \multicolumn{4}{|c|}{ Survival of S. frugiperda } & \multirow[t]{3}{*}{$\chi^{2}$} & \multirow[t]{3}{*}{$P$} \\
\hline & & & & & \multicolumn{2}{|c|}{ vs. S. albicosta } & \multicolumn{2}{|c|}{ vs. H. $z e a$} & & \\
\hline & S. frugiperda & Competitor & Live $(n)$ & $\%$ & Live $(n)$ & $\%$ & Live $(n)$ & $\%$ & & \\
\hline Silk & Small $^{a}$ & Small & $16(20)$ & 80.0 & $20(20)$ & 100.0 & $19(20)$ & 95.0 & 5.67 & 0.0586 \\
\hline Silk & Small & Large & $7(20)$ & 35.0 & $16(20)$ & 80.0 & $2(20)$ & 10.0 & 20.71 & $<0.0001$ \\
\hline Silk & Large & Small & $20(20)$ & 100.0 & $19(20)$ & 95.0 & $19(20)$ & 95.0 & 1.03 & 0.5962 \\
\hline Silk & Large & Large & $14(20)$ & 70.0 & $20(20)$ & 100.0 & $13(20)$ & 65.0 & 8.44 & 0.0147 \\
\hline Maize ear & Small & Small & $14(20)$ & 70.0 & $20(20)$ & 100.0 & $19(20)$ & 95.0 & 10.03 & 0.0066 \\
\hline Maize ear & Small & Large & $11(20)$ & 55.0 & $15(20)$ & 75.0 & $15(20)$ & 75.0 & 2.46 & 0.2916 \\
\hline Maize ear & Large & Small & $20(20)$ & 100.0 & $20(20)$ & 100.0 & $20(20)$ & 100.0 & - & - \\
\hline Maize ear & Large & Large & $17(20)$ & 85.0 & $19(20)$ & 95.0 & $20(20)$ & 100.0 & 3.75 & 0.1534 \\
\hline 1st Field & Small & Small & $15(25)$ & 60.0 & $25(25)$ & 100.0 & $21(25)$ & 84.0 & 13.35 & 0.0013 \\
\hline 1st Field & Small & Large & $19(25)$ & 76.0 & $21(25)$ & 84.0 & $19(25)$ & 76.0 & 0.63 & 0.7278 \\
\hline 1st Field & Large & Small & $25(25)$ & 100.0 & $25(25)$ & 100.0 & $25(25)$ & 100.0 & - & - \\
\hline 1st Field & Large & Large & $21(25)$ & 84.0 & $25(25)$ & 100.0 & $23(25)$ & 92.0 & 4.35 & 0.1137 \\
\hline 2nd Field & Small & Small & $20(25)$ & 80.0 & $18(18)$ & 100.0 & $24(25)$ & 96.0 & 6.35 & 0.0419 \\
\hline 2nd Field & Small & Large & $18(25)$ & 72.0 & $17(18)$ & 94.4 & $19(25)$ & 76.0 & 3.50 & 0.1733 \\
\hline 2nd Field & Large & Small & $25(25)$ & 100.0 & $18(18)$ & 100.0 & $25(25)$ & 100.0 & - & - \\
\hline 2nd Field & Large & Large & $22(25)$ & 88.0 & $18(18)$ & 100.0 & $18(25)$ & 72.0 & 6.77 & 0.0338 \\
\hline
\end{tabular}

${ }^{a}$ Small (second instar); Large (fourth instar); first size, S. frugiperda; second size, competitor.

larger than the competitor, survival was $100 \%$ and when competing as large versus large against $H$. zea, S. frugiperda survival was $100 \%$ (while the survival of $H$. zea in this scenario was $45 \%$; Table 3).

In the first field study, survival of $S$. frugiperda was significantly lower in small versus small intraspecific competition $\left(\chi^{2}=13.35\right.$; $\mathrm{df}=2 ; P=0.0013)$. In other scenarios of competition, there was no significant difference in survival of $S$. frugiperda, which was $>76 \%$. Survival of $S$. frugiperda was $100 \%$ when competition was large versus small (Table 3). The second field study was similar to the first, with survival of $S$. frugiperda in the small versus small scenario significantly lower in the control $\left(\chi^{2}=6.35 ; \mathrm{df}=2 ; P=0.0419\right)$. When larvae were in large size against other large size, the survival was higher competing against $S$. albicosta $\left(\chi^{2}=6.77 ; \quad \mathrm{df}=2\right.$; $P=0.0338$ ). In the other scenarios of competition, the survival of $S$. frugiperda did not differ and once again, their survival was $100 \%$ competing in large size against opponents in small size (Table 3).

On maize silk in the laboratory, survival of H. zea was significantly higher than $S$. albicosta in relation to competition with $S$. frugiperda and H. zea in all scenarios $(P<0.0001)$, with exception of large versus small, where there was no significant difference in survival. In the scenarios of small versus large and large versus large, there was $0 \%$ survival in intraspecific competition, reflecting the high rate of cannibalism (Table 4). On maize ears in the laboratory, 
Table 4. Intraguild competition scenarios between Helicoverpa zea against Striacosta albicosta, Spodoptera frugiperda, and in intraspecific competition, in maize silk and maize ear in laboratory, and in field

\begin{tabular}{|c|c|c|c|c|c|c|c|c|c|c|}
\hline \multirow[t]{3}{*}{ Diet } & \multirow{2}{*}{\multicolumn{2}{|c|}{ Competition }} & \multirow{2}{*}{\multicolumn{2}{|c|}{$\begin{array}{c}\text { Survival of H. zea (control) } \\
\text { vs. H. zea }\end{array}$}} & \multicolumn{4}{|c|}{ Survival of H. zea } & \multirow[t]{3}{*}{$\chi^{2}$} & \multirow[t]{3}{*}{$P$} \\
\hline & & & & & \multicolumn{2}{|c|}{ vs. S. albicosta } & \multicolumn{2}{|c|}{ vs. S. frugiperda } & & \\
\hline & H. zea & Competitor & Live $(n)$ & $\%$ & Live $(n)$ & $\%$ & Live $(n)$ & $\%$ & & \\
\hline Silk & Small $^{a}$ & Small & $1(20)$ & 5.0 & $17(20)$ & 85.0 & $3(20)$ & 15.0 & 33.41 & $<0.0001$ \\
\hline Silk & Small & Large & $0(20)$ & 0.0 & $10(20)$ & 50.0 & $0(20)$ & 0.0 & 24.00 & $<0.0001$ \\
\hline Silk & Large & Small & $20(20)$ & 100.0 & $18(20)$ & 90.0 & $19(20)$ & 95.0 & 2.10 & 0.3490 \\
\hline Silk & Large & Large & $0(20)$ & 0.0 & $14(20)$ & 70.0 & $9(20)$ & 45.0 & 21.29 & $<0.0001$ \\
\hline Maize ear & Small & Small & $5(20)$ & 25.0 & $20(20)$ & 100.0 & $10(20)$ & 50.0 & 24.00 & $<0.0001$ \\
\hline Maize ear & Small & Large & $4(20)$ & 20.0 & $13(20)$ & 65.0 & $5(20)$ & 25.0 & 10.48 & 0.0053 \\
\hline Maize ear & Large & Small & $20(20)$ & 100.0 & $20(20)$ & 100.0 & $19(20)$ & 95.0 & 2.03 & 0.3617 \\
\hline Maize ear & Large & Large & $6(20)$ & 30.0 & $19(20)$ & 95.0 & $9(20)$ & 45.0 & 18.87 & $<0.0001$ \\
\hline 1st Field & Small & Small & $0(25)$ & 0.0 & $25(25)$ & 100.0 & $17(25)$ & 68.0 & 52.92 & $<0.0001$ \\
\hline 1st Field & Small & Large & $2(25)$ & 8.0 & $24(25)$ & 96.0 & $2(25)$ & 8.0 & 55.17 & $<0.0001$ \\
\hline 1st Field & Large & Small & $25(25)$ & 100.0 & $25(25)$ & 100.0 & $24(25)$ & 96.0 & 2.03 & 0.3629 \\
\hline 1st Field & Large & Large & $2(25)$ & 8.0 & $24(25)$ & 96.0 & $4(25)$ & 16.0 & 49.33 & $<0.0001$ \\
\hline 2nd Field & Small & Small & $4(25)$ & 16.0 & $18(18)$ & 100.0 & $17(25)$ & 68.0 & 32.02 & $<0.0001$ \\
\hline 2nd Field & Small & Large & $4(25)$ & 16.0 & $16(18)$ & 88.9 & $7(25)$ & 28.0 & 25.49 & $<0.0001$ \\
\hline 2nd Field & Large & Small & $25(25)$ & 100.0 & $18(18)$ & 100.0 & $22(25)$ & 88.0 & 5.40 & 0.0673 \\
\hline 2nd Field & Large & Large & $3(25)$ & 12.0 & $18(18)$ & 100.0 & $4(25)$ & 16.0 & 42.19 & $<0.0001$ \\
\hline
\end{tabular}

${ }^{a}$ Small (second instar); Large (fourth instar); first size, H. zea; second size, competitor.

the survival of $H$. zea was significantly higher than $S$. albicosta for all competition scenarios $(P<0.05)$, again with exception to large versus small, where there was no difference between the competitions (Table 4).

For both field competition studies, the results were similar to those observed in the laboratory. There was significantly higher survival of $H$. zea than $S$. albicosta in all competition scenarios $(P<0.0001)$. There was significantly lower survival of $H$. zea in intraspecific (control) competition when the competition was between small versus small, small versus large, and large versus large in the two field competition studies, with a maximum survival of $16 \%$ (Table 4).

\section{Laboratory Cost Fitness}

Mean pupal weight of male $S$. frugiperda reared from small larvae not in competition with other larvae $(209.13 \mathrm{mg})$ was significantly greater than the pupal weight of small larvae surviving the competitions $(F=9.48 ; \mathrm{df}=4,52 ; P<0.0001$; Table 5$)$. The lowest $S$. frugiperda pupal weight $(156.5 \mathrm{mg})$ was observed when in competition with small S. albicosta. Mean pupal weight of female $S$. frugiperda reared from small larvae not in competition with other larvae $(202.97 \mathrm{mg})$ was significantly greater than the pupal weight of small larvae surviving the competitions $(F=6.07 ; \mathrm{df}=4,38 ; P=0.0007$; Table 5).

Mean pupal weight of male $S$. frugiperda reared from large larvae not in competition with other larvae $(181.91 \mathrm{mg})$ was significantly greater than the pupal weight of large larvae surviving the competition $(F=3.42 ; \mathrm{df}=6,60 ; P=0.0057)$, and the lowest pupal weight was observed when in competition with small $S$. albicosta $(150.91 \mathrm{~g})$. There was no significant difference in pupal weight between large competing and noncompeting female $S$. frugiperda $(F=2.20 ; \mathrm{df}=6,63 ; P=0.0549)$.

Mean pupal weights of $H$. zea did not significantly differ among noncompeting and competing larvae surviving competition as small males $(F=0.29 ; \mathrm{df}=3,22 ; P=0.8311)$, females $(F=1.19 ; \mathrm{df}=2$, $28 ; P=0.3203)$, or large males $(F=1.33 ; \mathrm{df}=4,34 ; P=0.2792$; Table 6). For large females, the greatest pupal weights were observed in the noncompeting (control) and when competing against S. albicosta (small and large), with $291.49 \mathrm{mg}, 288.03 \mathrm{mg}$, and $284.92 \mathrm{mg}$, respectively (Table 6).

We found no significant differences in pupal viability between different competition scenarios $(P>0.05$; Table 7$)$. Due to the low number of $S$. albicosta larvae that survived the competition study, it was not possible to evaluate this species for pupal weight and viability.

\section{Discussion}

Results from the competition studies conducted in the laboratory, particularly those conducted on maize ears in containers, were similar to those in the field, indicating that the laboratory conditions did not compromise the larval competitions. Because of the biological characteristics of the noctuids assessed, the occurrence of intraguild competition among them is relatively common, yet has been scarcely documented or studied at the field level. Many species of Lepidoptera, including $S$. frugiperda, are attracted to volatile organic compounds emitted by injured plants and by conspecific larvae (Von Mérey et al. 2013). This behavior represents a kind of "trap" for larvae, which have to deal with competition, the risk of cannibalism and predation, and even with the attack of natural enemies that are also attracted by these volatiles (Von Mérey et al. 2013).

Results of the interspecific competition indicated that S. albicosta is highly affected and preyed upon by the competitor species (Table 2). When the competitions are between small versus small, small versus large, and large versus large, the mortality rate of $S$. albicosta is higher than when it occurs between large versus small. This was expected because the larva is more developed (in case $S$. albicosta) than the competitor, so the occurrence of predation is reduced, although it can still occur. In addition, the development of $S$. albicosta is generally slower than the other species under the same conditions (Antonelli 1974, Butler 1976, Sparks 1979), which likely allows the more rapidly developing competitor species to gain an advantage in the competition with S. albicosta. 
Table 5. LSMean ( \pm SE of LSMean) of pupal weight $(\mathrm{mg})$ of Spodoptera frugiperda developed in different competition scenarios beginning in small and large size

\begin{tabular}{|c|c|c|c|c|c|}
\hline \multicolumn{2}{|l|}{ Competition scenario } & \multicolumn{2}{|r|}{ Male } & \multicolumn{2}{|c|}{ Female } \\
\hline Species & vs. Competitor species & $n^{a}$ & Pupal weight $(\mathrm{mg})^{b}$ & $n^{a}$ & Pupal weight $(\mathrm{mg})^{b}$ \\
\hline \multirow[t]{7}{*}{ S. frugiperda (small) } & - & 10 & $209.13 \pm 6.78 \mathrm{a}$ & 10 & $202.97 \pm 6.21 \mathrm{a}$ \\
\hline & S. frugiperda (small) & 20 & $169.30 \pm 4.79 b c$ & 11 & $173.09 \pm 5.92 b$ \\
\hline & S. frugiperda (large) & 3 & $177.80 \pm 12.38 \mathrm{c}$ & 2 & $137.60 \pm 13.90 \mathrm{c}$ \\
\hline & H. zea (small) & 10 & $161.20 \pm 6.78 \mathrm{bc}$ & 8 & $160.49 \pm 6.95 b$ \\
\hline & H. zea (large) & 2 & $198.50 \pm 15.16 \mathrm{c}$ & 1 & $209.7 \pm 19.66 c$ \\
\hline & S. albicosta (small) & 12 & $156.50 \pm 6.19 c$ & 6 & $181.73 \pm 8.02 \mathrm{~b}$ \\
\hline & S. albicosta (large) & 5 & $180.00 \pm 9.59 b$ & 8 & $170.26 \pm 6.95 b$ \\
\hline$P$ & & & $<0.0001$ & & 0.0002 \\
\hline \multirow[t]{7}{*}{ S. frugiperda (large) } & - & 10 & $181.91 \pm 5.28 \mathrm{a}$ & 10 & $182.46 \pm 7.08$ \\
\hline & S. frugiperda (small) & 9 & $170.84 \pm 3.83 \mathrm{ab}$ & 9 & $161.93 \pm 6.21$ \\
\hline & S. frugiperda (large) & 19 & $169.87 \pm 5.56 \mathrm{abc}$ & 13 & $183.20 \pm 7.46$ \\
\hline & H. zea (small) & 7 & $177.87 \pm 6.31 \mathrm{ab}$ & 11 & $163.75 \pm 6.75$ \\
\hline & H. zea (large) & 4 & $170.35 \pm 8.34 \mathrm{abc}$ & 7 & $156.44 \pm 8.46$ \\
\hline & S. albicosta (small) & 9 & $150.91 \pm 5.56 c$ & 10 & $159.04 \pm 7.08$ \\
\hline & S. albicosta (large) & 9 & $161.71 \pm 5.56 \mathrm{bc}$ & 10 & $169.73 \pm 7.08$ \\
\hline$P$ & & & 0.0057 & & 0.0549 \\
\hline
\end{tabular}

${ }^{a} \mathrm{n}$, number of insects evaluated.

${ }^{b}$ Original data. Means followed by the same letter per column do not differ by LSD test $(P>0.05)$.

Table 6. LSMean ( \pm SE of LSMean) of pupal weight $(\mathrm{mg})$ of Helicoverpa zea developed in different competition scenarios beginning in small and large size

\begin{tabular}{|c|c|c|c|c|c|}
\hline \multicolumn{2}{|c|}{ Competition scenario } & \multicolumn{2}{|c|}{ Male } & \multicolumn{2}{|c|}{ Female } \\
\hline Species & vs. Competitor species & $n^{a}$ & Pupal weight $(\mathrm{mg})^{b}$ & $n^{a}$ & Pupal weight $(\mathrm{mg})^{b}$ \\
\hline \multirow[t]{7}{*}{ H. zea (small) } & - & 8 & $270.58 \pm 9.78$ & 12 & $281.46 \pm 9.0$ \\
\hline & H. zea (small) & 7 & $281.93 \pm 10.45$ & 2 & $292.40 \pm 14.50$ \\
\hline & H. zea $(\text { large })^{c}$ & - & - & - & - \\
\hline & S. frugiperda (small) & 1 & $312.30 \pm 27.66$ & 1 & $290.00 \pm 0.0$ \\
\hline & S. frugiperda $(\text { large })^{c}$ & - & - & - & - \\
\hline & S. albicosta (small) & 4 & $279.88 \pm 13.83$ & 8 & $287.69 \pm 4.62$ \\
\hline & S. albicosta (large) & 7 & $271.53 \pm 10.45$ & 11 & $295.27 \pm 3.09$ \\
\hline$P$ & & & 0.8311 & & 0.3203 \\
\hline \multirow[t]{7}{*}{ H. zea (large) } & - & 11 & $274.66 \pm 12.84$ & 9 & $291.49 \pm 10.38 \mathrm{a}$ \\
\hline & H. zea (small) & 7 & $241.29 \pm 16.10$ & 6 & $245.57 \pm 12.71 b$ \\
\hline & H. zea (large) & 7 & $254.51 \pm 16.10$ & 4 & $274.78 \pm 15.57 \mathrm{ab}$ \\
\hline & S. frugiperda (small) & 2 & $299.05 \pm 30.12$ & 8 & $246.26 \pm 11.01 b$ \\
\hline & S. frugiperda (large) & 2 & $302.30 \pm 30.12$ & 4 & $236.85 \pm 15.57 b$ \\
\hline & S. albicosta (small) & 6 & $266.28 \pm 17.39$ & 5 & $284.92 \pm 13.93 a$ \\
\hline & S. albicosta (large) & 8 & $285.64 \pm 15.06$ & 6 & $288.03 \pm 12.71 \mathrm{a}$ \\
\hline$P$ & & & 0.2792 & & 0.0098 \\
\hline
\end{tabular}

${ }^{a} n$, number of insects evaluated.

${ }^{b}$ Original data. Means followed by the same letter per column do not differ by LSD test $(P>0.05)$.

${ }^{c}$ The treatment did not support survival to the adult stage in a significant number of individuals, thus was excluded from the statistical analysis.

In general, the survival of $S$. albicosta was greater in the arenas of maize ears than in plastic containers with maize silk. The higher survival was probably related to the greater quality and quantity of food provided to the larvae (Paula-Moraes et al. 2012). In addition, the bigger surface area of the maize ear may have resulted in fewer encounters between the larvae, or allowed S. albicosta to escape from competitors. For example, in interspecific competition scenarios on the maize ear, it was often observed that the larvae were well separated from one another, which may have occurred after aggressive encounters between $S$. albicosta and the competitors.

The intraspecific competition of S. albicosta did not result in high rate of cannibalism, and the survival rate of individuals was greater than $80 \%$ regardless of the competition scenario. The $20 \%$ mortality in the first field bioassay was attributed to natural mortality of larvae, and not to cannibalism. Natural mortality of S. albicosta in Nebraska has been documented between 56.5 and $98.5 \%$ (Hirnyck 1983), and in a recent study S. albicosta larvae had 
Table 7. LSMean ( \pm SE of LSMean) of pupal viability (\%) of Spodoptera frugiperda and Helicoverpa zea reared in different competition scenarios beginning in small size and large size

\begin{tabular}{|c|c|c|c|}
\hline \multicolumn{2}{|l|}{ Competition scenario } & \multirow[t]{2}{*}{$n^{a}$} & \multirow[t]{2}{*}{ Pupal survival $(\%)^{b}$} \\
\hline Species & vs. Competitor species & & \\
\hline \multirow[t]{7}{*}{ S. frugiperda (small) } & - & 20 & $85.00 \pm 6.81$ \\
\hline & S. frugiperda (small) & 31 & $96.77 \pm 5.47$ \\
\hline & S. frugiperda (large) & 5 & $80.00 \pm 13.63$ \\
\hline & H. zea (small) & 18 & $77.78 \pm 7.18$ \\
\hline & H. zea (large) & 2 & $100.00 \pm 21.55$ \\
\hline & S. albicosta (small) & 18 & $94.44 \pm 7.18$ \\
\hline & S. albicosta (large) & 13 & $92.31 \pm 8.45$ \\
\hline$P$ & & & 0.4124 \\
\hline \multirow[t]{7}{*}{ S. frugiperda (large) } & - & 20 & $95.00 \pm 7.56$ \\
\hline & S. frugiperda (large) & 26 & $76.92 \pm 6.63$ \\
\hline & S. frugiperda (small) & 18 & $83.33 \pm 7.97$ \\
\hline & H. zea (small) & 18 & $83.33 \pm 7.97$ \\
\hline & H. zea (large) & 11 & $90.91 \pm 10.20$ \\
\hline & S. albicosta (small) & 19 & $89.47 \pm 7.76$ \\
\hline & S. albicosta (large) & 19 & $94.74 \pm 7.76$ \\
\hline$P$ & & & 0.5360 \\
\hline \multirow[t]{7}{*}{ H. zea (small) } & - & 20 & $85.00 \pm 7.00$ \\
\hline & H. zea (small) & 9 & $66.67 \pm 10.44$ \\
\hline & H. zea $(\text { large })^{c}$ & - & - \\
\hline & S. frugiperda (small) & 2 & $100.0 \pm 22.14$ \\
\hline & S. frugiperda (large $)^{c}$ & - & - \\
\hline & S. albicosta (small) & 12 & $100.0 \pm 9.04$ \\
\hline & S. albicosta (large) & 18 & $94.44 \pm 7.38$ \\
\hline$P$ & & & 0.1438 \\
\hline \multirow[t]{7}{*}{ H. zea (large) } & - & 20 & $85.0 \pm 7.79$ \\
\hline & H. zea (large) & 11 & $76.92 \pm 9.66$ \\
\hline & H. zea (small) & 13 & $72.73 \pm 10.50$ \\
\hline & S. frugiperda (small) & 10 & $80.00 \pm 11.02$ \\
\hline & S. frugiperda (large) & 6 & $83.33 \pm 14.22$ \\
\hline & S. albicosta (small) & 11 & $100.0 \pm 9.66$ \\
\hline & S. albicosta (large) & 14 & $100.0 \pm 9.31$ \\
\hline$P$ & & & 0.3455 \\
\hline
\end{tabular}

${ }^{a} n$, number of insects evaluated.

${ }^{b}$ Original data. Means followed by the same letter per column do not differ by LSD test $(P>0.05)$.

${ }^{c}$ The treatment did not support survival to the adult stage in a significant number of individuals, thus was excluded from the statistical analysis.

survival rates ranging from 45 to $66 \%$ when were fed from neonates with maize silk (Paula-Moraes et al. 2012).

The presence of more than one larva of S. albicosta per maize ear has been reported (Seymour et al. 2004), although numbers this high are rare. If the maize silks or kernels in the ear tip have already been consumed by one of their "sisters", S. albicosta larvae will enter the ear through the husk on the side of the same maize ear (Cullen and Jyoti 2008), which was observed in this bioassay; however, many times both larvae were found in the ear feeding in proximity in the ear tip.

Regarding S. frugiperda, cannibalism of this specie has already been well documented, both under field and laboratory conditions (Chapman et al. 1999a,b, 2000; Goussain et al. 2002). In the present study, high larval survival when competing as small $S$. frugiperda versus a small competitor, and as large $S$. frugiperda versus a small competitor indicates that this specie has a high capacity to compete with other species. However, when large versus large competitors, and when smaller than the competitor, the results suggest that the specie may be negatively affected under intraguild competition, unless the competitor is S. albicosta. Again this demonstrates low aggressiveness of $S$. albicosta in relation to the others species. In small versus small, for all competition scenarios, the survival of $S$. frugiperda was higher in interspecific competition than in intraspecific competition, which demonstrates the high occurrence of cannibalism of $S$. frugiperda and its ability to compete with other species.

Results between small $S$. frugiperda versus large competitor (laboratory and field) on maize ear competition scenarios were different than in maize silk scenarios (Table 3), with lower cannibalism and predation on maize ears and higher cannibalism and predation in maize silk. This may be related to characteristics of the competition arena (fewer encounters and greater possibility of escape on the maize ear than in maize silk) and that silk provided less nutritional value than maize ears. Previous studies reported that cannibalism rates are higher when the larvae are reared on maize leaves than when reared on artificial diet, suggesting that the cannibalistic behavior may be because of the lack of food with high nutritional value (Nalim 1991).

Third-instar S. frugiperda cannibalism rates were $\sim 18 \%$ when confined to maize seedlings, and increased to $34 \%$ when there was a shortage of food (Raffa 1987). In another study, the rate of cannibalism reached $100 \%$ when $S$. frugiperda larvae were confined in Petri dishes (Nalim 1991). In a study involving $S$. frugiperda larvae fed with maize leaves treated with silicon, there was a higher percentage of cannibalism on silico-treated leaves than nontreated leaves. The layer of silicon deposited on the leaf probably made it difficult the access to the food source, thus inducing high rates of cannibalism. These results demonstrate that $S$. frugiperda has accentuated cannibalistic behavior when food quality is limited (Goussain et al. 2002).

In competition scenario of large $S$. frugiperda versus a small competitor, larval survival was very high, as expected. In large $S$. frugiperda versus large competitor, survival also remained high, with exception of the second field competition where $S$. frugiperda was negatively affected by competing with $H$. zea. However, in the same competition, the survival of $H$. zea was lower than that of $S$. frugiperda, again suggesting the tendency of this $S$. frugiperda to prevail over the other two species.

As $H$. zea and S. frugiperda exhibit cannibalistic behavior, the results of the competition between the two was expected. According to the literature, $H$. zea typically begin feeding on silks and kernel at the ear tip before consuming kernels down the maize ear, whereas fall armyworm will burrow through the ear tip, husk, or shank (Buntin 1986). These behaviors were often observed in the field in this study, and the incidence of predation was commonly found, with prevalence of $S$. frugiperda between both species. According to the characteristics of insects that occur in maize crops in the United States, H. zea larvae that occur late in the maize cycle can invade maize ears without feeding on maize silks (Burkness et al. 2010). Thus, it is assumed that if the two species occur simultaneously in the same plant, there is greater probability of $S$. frugiperda be more developed than $H$. zea because $S$. frugiperda tends to infest the plant earlier (vegetative stage) and then migrates to the maize ear, whereas H. zea occurs during a later period (reproductive stage), so is generally in a less developed phase.

The survival of $H$. zea was high only when competing with $S$. albicosta (Table 4). In the intraspecific scenarios, the mortality rate was high (Table 4), with exception of the scenario of large H. zea versus small $H$. zea, where the larger larvae cannibalized the smaller 
larvae in most of the competitions (Table 4). Taking into account the rate of larval survival in controls of $S$. frugiperda and H. zea, the high rate of cannibalism submitted by $H$. zea, suggested that it is more aggressive larvae than $S$. frugiperda and that cannibalism is frequent in $H$. zea intraguild competitions. In Noctuidae, cannibalism is dependent on the instar, with a tendency to occur more frequently in larger (more developed) than smaller larvae, especially when larvae of different stages are placed together (Polis 1981; Joyner and Gould 1985; Chapman et al. 1999a,b; O'Rourke and Hutchison 2000, 2004; Horner et al. 2003; Chilcutt 2006). Studies have shown that the cannibalism can represent up to $75 \%$ of $\mathrm{H}$. zea mortality (Chilcutt 2006). There can be more than one egg laid on a specific maize silk, but generally only one larva can survive per ear. This reinforces the importance of cannibalism on population regulation of H. zea (Chilcutt 2006).

The advantages and disadvantages of cannibalism and predation on larval development has been the subject of debate. Some authors advocate the theory that larvae who end up practicing cannibalism may have lower survival by suffering injuries and death, acquiring pathogens or parasites, having subsequent reduction in fitness, lower pupal weight, and lower rates of development depending on the availability of food (Fox 1975; Polis 1981; Pfennig et al. 1993; Chapman et al. 1999a,b; Rudolf and Antonovics 2007). However, when food is limited, cannibalism may benefit an individual, in which preying others can result in fitness benefits and increase the rate of development, body mass, and fecundity (Polis 1981, Joyner and Gould 1985, Kakimoto et al. 2003). In addition, a possible indirect benefit of both intraguild predation and cannibalism is the reduction in the intensity of exploitative competition through elimination of a potential competitor, resulting in greater availability of food (Polis 1988). It is worth noting that although many authors see cannibalism as a form of intraguild predation, there is the hypothesis that they are different, as cannibalism can cause direct genetic costs, which does not occur in intraguild predation. Cannibalism rates tend to increase with an increase in larval population density (Chapman et al. 1999b). When the individuals are reared at high density, they tend to differ from conspecifics reared at low density. Several characteristics, such as color, behavior, larval development time, and pupal size, may result in higher susceptibility to diseases. Intraspecific competition caused by reduced food supply is considered to be one of causes of these changes (Pener 1991, Goulson and Cory 1995). This study did not evaluate the larval attack or defense behaviors, which may have resulted in significant injury to individuals and caused their death, but it was possible to evaluate the direct feeding of one larva on another in the bioassay with maize silk where assessments were made daily. More detailed studies, with the completion of an ethogram, are needed to fully understand larval aggressive and defensive behaviors.

The pupal weight of $S$. frugiperda and female H. zea in the large size (Table 5) suggest that larvae that did not suffer from food competition, did not have the opportunity of preying on the competitor, experienced improved development, as they did not suffer attacks and therefore avoid the need to defend themselves. Thus, under the conditions of this study, using only maize silk as food, lack of competition and cannibalism was advantageous for the development of $S$. frugiperda and $H$. zea females. Although not been presented as beneficial, there was the assumption that if the cannibalism and predation would be advantageous to the fitness of the insects, the positive effects would be more expressed when occurring earlier in the larval developmental period, as the individual could have the indirect benefits of this behavior the majority of time, and when it occurs during a late period of the life of the insect, the benefits may be lower (Johansson 1996).

In general, this study indicated that survival of S. albicosta is negatively affected when this species competes against $S$. frugiperda and H. zea. On the other hand, S. frugiperda has high survival and a competitive advantage when competing with the other species studied. The relations of intraguild competition and cannibalism and predation between Noctuidae on maize demand further study focusing on the potential impact of these relations on the biology and life history of these insects in the field. The development of new maize hybrids expressing different Bt proteins and gene pyramids, together with the adoption of a seed mixture refuge strategy (refuge-in-thebag or RIB) and cross-pollination resulting in sublethal doses of $\mathrm{Bt}$ (Burkness et al. 2011), intensifies the need for studies involving the behavior of lepidopterans of the same guild (US-EPA 2010, Onstad et al. 2011, Matten et al. 2012).

\section{Acknowledgments}

We thank Logan Dana and Lynn Junck for the technical support, and the Coordination for the Improvement of Higher Education Personnel (CAPES99999.002564/2014-09) and the National Council for Scientific and Technological Development (CNPq-305649/2013-2) for the financial support.

\section{References Cited}

Alabi, T., S. Patiny, F. Verheggen, F. Francis, and E. Haubruge. 2009. Origine et evolution du cannibalisme dans les populations animals: pourquoi manger son semblable? Biotechnol. Agron. Soc. Environ. 13: 409-425.

Antonelli, A. L. 1974. Resistance of Phaseolus vulgaris cultivars to western bean cutworm, Loxagrotis albicosta (Smith), with notes on the bionomics and culture of the cutworm. Ph.D. dissertation, University of Idaho, Idaho.

Binning, R. R., J. Coats, X. Kong, and R. L. Hellmich. 2014. Susceptibility and aversion of Spodoptera frugiperda (Lepidoptera: Noctuidae) to Cry1F Bt maize and considerations for insect resistance management. J. Econ. Entomol. 107: 368-374.

Buntin, G. D. 1986. A review of plant response to fall armyworm, Spodoptera frugiperda (J.E. Smith), injury in selected field and forage crops. Fla. Entomol. 74: 549-559.

Burkness, E. C., and W. D. Hutchison. 2012. Bt pollen dispersal and Bt kernel mosaics: Integrity of non-Bt refugia for lepidopteran resistance management in maize. J. Econ. Entomol. 105: 1773-1780.

Burkness, E. C., G. P. Dively, T. Patton, A. C. Morey, and W. D. Hutchison. 2010. Novel Vip3A Bacillus thuringiensis ( $\mathrm{Bt}$ ) maize approaches high dose efficacy against Helicoverpa zea (Lepidoptera: Noctuidae) under field conditions: implications for resistance management. GM Crops 1: 337-343.

Burkness, E. C., P. K. O’Rourke, and W. D. Hutchison. 2011. Cross-pollination of nontransgenic corn ears with transgenic Bt corn: Efficacy against lepidopteran pests and implications for resistance management. J. Econ. Entomol. 104: 1476-1479.

Butler, G. D. Jr. 1976. Bollworm: development in relation to temperature and larval food. Environ. Entomol. 5: 520-522.

Catangui, M. A., and R. K. Berg. 2006. Western bean cutworm, Striacosta albicosta (Smith) (Lepidoptera: Noctuidae), as a potential pest of transgenic Cry1Ab Bacillus thuringiensis corn hybrids in South Dakota. Environ. Entomol. 35: 1439-1452.

Chapman, J. W., T. Williams, A. Escribano, P. Caballero, R. D. Cave, and D. Goulson. 1999a. Age-related cannibalism and horizontal transmission of a nuclear polyhedrosis virus in larval Spodoptera frugiperda. Ecol. Entomol. 24: 268-275.

Chapman, J. W., T. Williams, A. Escribano, P. Caballero, R. D. Cave, and D. Goulson. 1999b. Fitness consequences of cannibalism in the fall armyworm, Spodoptera frugiperda. Behav. Ecol. 10: 298-303. 
Chapman, J. W., T. Williams, A. M. Martínez, J. Cisneros, P. Caballero, R. D. Cave, and D. Goulson. 2000. Does cannibalism in Spodoptera frugiperda (Lepidoptera: Noctuidae) reduce the risk of predation? Behav. Ecol. Sociobiol. 48: 321-327.

Chilcutt, C. F. 2006. Cannibalism of Helicoverpa zea (Lepidoptera: Noctuidae) from Bacillus thuringiensis (Bt) transgenic corn versus non- $\mathrm{Bt}$ corn. J. Econ. Entomol. 99: 728-732.

Chilcutt, C. F., and B. E. Tabashnik. 2004. Contamination of refuges by Bacillus thuringiensis toxin genes from transgenic maize. Proc. Natl. Acad. Sci. USA. 101: 7526-7529.

Chilcutt, C. F., G. N. Odvody, J. C. Correa, and J. Remmers. 2007. Effects of Bacillus thuringiensis transgenic corn on corn earworm and fall armyworm (Lepidoptera: Noctuidae) densities. J. Econ. Entomol. 100: 327-334.

Cullen, E., and J. Jyoti. 2008. Western bean cutworm: A pest of field and sweet corn (A3856) University of Wisconsin-System Board of Regents and University of Wisconsin-Extension, Cooperative Extension Wisconsin.

DiFonzo, C. D., and R. Hammond. 2008. Range expansion of western bean cutworm, Striacosta albicosta (Noctuidae), into Michigan and Ohio. Online. Crop Manag. doi:10.1094/CM-2008-0519-01-BR.

Dorhout, D. L., and M. E. Rice. 2004. First report of western bean cutworm, Richia albicosta (Noctuidae) in Illinois and Missouri. Online. Crop Manag.

Dorhout, D. L., and M. E. Rice. 2010. Intraguild competition and enhanced survival of western bean cutworm (Lepidoptera: Noctuidae) on transgenic Cry1Ab Bt corn. J. Econ. Entomol. 103: 54-62.

Douglass, J. R., J. W. Ingram, K. E. Gibson, and W. E. Peay. 1957. The western bean cutworm as a pest of corn in Idaho. J. Econ. Entomol. 50: 543-545.

Eickwort, K. R. 1973. Cannibalism and kin selection in Labidomera clivicolis (Coleoptera: Chrysomelidae). Am. Nat. 107: 452-453.

Elgar, M., and J. Crespi. 1992. Cannibalism: ecology and evolution among diverse taxa. Oxford University Press, Oxford, United Kingdom.

Fox, L. 1975. Cannibalism in natural populations. Annu. Rev. Ecol. Syst. 6: 87-106.

Goulson, D., and J. S. Cory. 1995. Responses of Mamestra brassicae (Lepidoptera: Noctuidae) to crowding: Interactions with disease resistance, colour phase and growth. Oecologia 104: 416-423.

Goussain, M. M., J. C. Moraes, J. G. Carvalho, N. L. Nogueira, and M. L. Rossi. 2002. Efeito da aplicação de silício em plantas de milho no desenvolvimento biológico da lagarta-do-cartucho Spodoptera frugiperda (J.E.Smith) (Lepidoptera: Noctuidae). Neotrop. Entomol. 1: 305-310.

Hagen, A. F. 1962. The biology and control of the western bean cutworm in dent corn in Nebraska. J. Econ. Entomol. 55: 628-631.

Hirnyck, R. E. 1983. Management of banks grass mite, Oligonychus pratensis (Banks), in field corn treated with insecticides for control of western bean cutworm, Loxagrotis albicosta (Smith). M.S. thesis, University of Nebraska, Nebraska.

Horner, T. A., G. P. Dively, and D. A. Herbert. 2003. Development, survival and fitness performance of Helicoverpa zea (Lepidoptera: Noctuidae) in MON-810 Bt field corn. J. Econ. Entomol. 96: 914-924.

Hutchison, W. D., E. C. Burkness, P. D. Mitchell, R. D. Moon, T. W. Leslie, S. J. Fleischer, M. Abrahamson, K. L. Hamilton, K. L. Steffey, M. E. Gray, et al. 2010. Areawide suppression of European corn borer with Bt maize reaps savings to non-Bt maize growers. Science 330: 222-225.

Hutchison, W. D., T. E. Hunt, G. L. Hein, K. L. Steffey, C. D. Pilcher, and M. E. Rice. 2011. Genetically engineered Bt corn and range expansion of the western bean cutworm (Lepidoptera: Noctuidae) in the United States: A response to Greenpeace Germany. J. Integr. Pest Manag. 2: B1-B8.

Johansson, F. 1996. The influence of cannibalism and prey density on growth in the damselfly Coenagrion hastulatum. Arch. Hydrobiol. 137: 523-535.

Joyner, K., and F. Gould. 1985. Developmental consequences of cannibalism in Heliothis zea (Lepidoptera: Noctuidae). Ann. Entomol. Soc. Am. 78: 24-28.

Kakimoto, T., K. Fujisaki, and T. Miyatake. 2003. Egg laying preference, larval dispersion, and cannibalism in Helicoverpa armigera (Lepidoptera: Noctuidae). Ann. Entomol. Soc. Am. 96: 793-798.

Malo, E. A., J. C. Rojas, R. Gago, and A. Guerrero. 2013. Inhibition of the responses to sex pheromone of the fall armyworm, Spodoptera frugiperda. J. Insect Sci. 13: 1-14.
Matten, S. R., R. J. Frederick, and A. H. Reynolds. 2012. United States Environmental Protection Agency insect resistance management programs for plant incorporated protectants and use of simulation modeling, pp. 175-267. In C. A. Wozniak and A. McHughen (eds.), Regulation of agricultural biotechnology: The United States and Canada. Springer Netherlands.

Michel, A. P., C. H. Krupke, T. S. Baute, and C. D. DiFonzo. 2010. Ecology and management of the western bean cutworm, Striacosta albicosta (Smith) (Lepidoptera: Noctuidae), in corn and dry beans. J. Integ. Pest Manag. 1: A1-A10.

Nalim, D. M. 1991. Biologia, nutrição quantitativa e controle de qualidade de populações de Spodoptera frugiperda (J. E. Smith, 1797) (Lepidoptera: Noctuidae) em duas dietas artificiais. Ph. D. dissertation. Escola Superior de Agricultura "Luiz de Queiroz" - Universidade de São Paulo, p. 150.

O'Rourke, P. K., and W. D. Hutchison. 2000. First report of the western bean cutworm (Lepidoptera: Noctuidae) in Minnesota corn. J. Agric. Urban Entomol. 17: 213-217.

O'Rourke, P. K., and W. D. Hutchison. 2004. Developmental delay and evidence for reduced cannibalism in corn earworm (Lepidoptera: Noctuidae) larvae feeding on transgenic Bt sweet corn. J. Entomol. Sci. 39: 294-297.

Onstad, D. W., P. D. Mitchell, T. M. Hurley, J. G. Lundgren, R. P. Porter, C. H. Krupke, J. L. Spencer, C. D. DiFonzo, T. S. Baute, R. L. Hellmich, et al. 2011. Seeds of change: Corn seed mixtures for resistance management and IPM. J. Econ. Entomol. 104: 343-352.

Paula-Moraes, S. V., T. E. Hunt, R. J. Wright, G. L. Hein, and E. E. Blankenship. 2012. On-Plant movement and feeding of western bean cutworm (Lepidoptera: Noctuidae) early instars on corn. J. Econ. Entomol. 41: 1494-1500.

Paula-Moraes, S. V., T. E. Hunt, R. J. Wright, G. L. Hein, and E. E. Blankenship. 2013. Western bean cutworm survival and the development of economic injury levels and economic thresholds in field corn. J. Econ. Entomol. 106: 1274-1285.

Pener, M. P. 1991. Locust phase polymorphism and its endocrine relations. Adv. Insect Physiol. 23: 1-79.

Pfennig, D. W., H. K. Reeve, and P. W. Sherman. 1993. Kin recognition and cannibalism in spadefoot toad tadpoles. Anim. Behav. 46: 87-94.

Pierce, N. E. 1995. Predatory and parasitic Lepidoptera: Carnivores living on plants. J. Lepid. Soc. 49: 412-453.

Polis, G. 1981. The evolution and dynamics of intraspecific predation. Annu. Rev. Ecol. Syst. 12: 125-151.

Polis, G. A. 1988. Exploitation competition and the evolution of interference, cannibalism, and intraguild predation in age/size-structured populations, pp. 185-202. In B. Ebenman (ed.), Size- Structured Populations: Ecology and Evolution. Berlin: Springer-Verlag, p. 284.

Raffa, K. F. 1987. Effect of host plant on cannibalism rates by fall armyworm (Lepidoptera: Noctuidae) larvae. Environ. Entomol. 16: 672-675.

Rice, M. E. 2000. Western bean cutworm hits northwest Iowa. Integrated Crop Management IC-484. Iowa State University Extension, Ames, IA, 22: 163.

Rice, M. E., and D. L. Dorhout. 2006. Western bean cutworm in Iowa, Illinois, Indiana and now Ohio: Did biotech corn influence the spread of this pest? pp. 165Đ172. In Proceedings of the 18th Annual Integrated Crop Management Conference, Iowa State University, Ames, IA.

Ritchie, S. W., J. J. Hanway, and G. O. Benson. 1993. How a corn plant develops. Special Report Number 48. Iowa State University of Science and Technology, Ames, IA.

Root, R. 1967. The niche exploitation pattern of the bluegrey gnatcatcher. Ecol. Mono. 37: 317-350.

Rudolf, V. H., and J. Antonovics. 2007. Disease transmission by cannibalism: Rare event or common occurrence? Proc. R. Soc. B Biol. Sci. 274: 1205-1210.

Rule, D. M., S. P. Nolting, P. L. Prasifka, N. P. Storer, B. W. Hopkins, E. F. Scherder, M. W. Siebet, and W. H. Hendrix. 2014. Efficacy of pyramided Bt proteins Cry1F, Cry1A.105, and cry2Ab2 expressed in Smartstax corn 
hybrids against lepidopteran insect pests in the northern United States. J. Econ. Entomol. 107: 403-409.

SAS Institute. 2011. SAS/STAT 9.3. SAS Institute, Cary, NC.

Seymour, R. C., G. L. Hein, R. J. Wright, and J. B. Campbell. 2004. Western bean cutworm in corn and dry beans. NebGuide G1359, University of Nebraska, Lincoln, NE.

Siebert, M. W., S. P. Nolting, W. Hendrix, S. Dhavala, C. Craig, B. R. Leonard, S. D. Stewart, J. All, F. R. Musser, G. D. Buntin, et al. 2012. Evaluation of corn hybrids expressing Cry1F, Cry1A.105, Cry2Ab2, Cry34Ab1/Cry35Ab1, and Cry3Bb1 against southern United States insect pests. J. Econ. Entomol. 105: 1825-1834.

Sparks, A. N. 1979. A review of the biology of the fall armyworm. Fla. Entomol. 62: 82-87.
(US-EPA) United States Environmental Protection Agency. 2010. Terms and Conditions for Bt Corn Registrations 30 Sept 2010. Office of Pesticide Programs, Washington, DC.

(USDA FAZ) United States Department of Agriculture Foreign Agricultural Service. 2014. World agricultural Production (01-14). United States department of agriculture, Washington, DC.

Von Mérey, G. E., N. Veyrat, M. D’Alessandro, and T.C.J. Turlings. 2013. Herbivore-induced maize leaf volatiles affect attraction and feeding behavior of Spodoptera littoralis caterpillars. Front. Plant. Sci. 4: 1-9.

Winer, B. J., D. R. Brown, K. M. Michels. 1991. Statistical principles in experimental design. McGraw-Hill, New York, NY.

Wise, D. H. 2006. Cannibalism, food limitation, intraspecific competition, and the regulation of spider populations. Annu. Rev. Entomol. 51: 441-465. 